\title{
Encomienda, hacienda y orden rural en el norte argentino: Jujuy 1850-1900
}

Gustavo L. Paz

University of Nebraska

\begin{abstract}
El presente trabajo estudia la relación entre la hacienda y la encomienda en el norte argentino (Jujuy) y el establecimiento del orden rural por parte del estado en la segunda mitad del siglo XIX. Si bien las encomiendas habían sido abolidas en Argentina por la legislación republicana a comienzos de ese siglo, en Jujuy se dio un interesante y anacrónico debate sobre la continuidad de la encomienda y los derechos que otorgaba a la propiedad de la tierra. Este debate fue resuelto por la justicia federal, que abrió la posibilidad al Estado provincial de ejercer su autoridad sobre vastas regiones rurales y, eventualmente, obtener recursos de la venta de tierras fiscales. La política estatal benefició la reconstitución de las haciendas y, con escasas excepciones, frenó el acceso de los campesinos a la propiedad de la tierra.
\end{abstract}

PALABRAS ClaVE: Hacienda-encomienda-campesinos-orden rural.

This paper is aimed at studying the relationship between large rural estates (haciendas) and encomiendas in northern Argentina (Jujuy) and the establishment of order in the countryside by te State in the second half of the nineteenth century. Even though encomiendas had been abolished in Argentina by Republican legislation at the beginning of that century, an interesting and anachronistic debate developped in Jujuy on the continuity of encomienda and the rights it bestowed upon land ownership. This debate was resolved by the Federal Justice which gave to the provincial State the chance of exerting its control on vast rural areas as well as benefitting from the eventual sale of fiscal lands. The State's policies favoured the reconstitution of haciendas and, with few exceptions, hindered the peasants' access to land ownership.

KEYWORDS: Large estate-encomienda-peasants-rural order.

\section{Introducción}

A mediados de la década de 1870 se desarrolló en la Argentina un áspero y bastante anacrónico debate acerca de la naturaleza y relación de la hacienda y la encomienda. El caso particular era la disputa por la propiedad de la finca y ex-encomienda Casabindo y Cochinoca que, con unas 200.000 hectáreas de superficie, se ubicaba en la puna de la norteña provincia de Jujuy, en la frontera con las repúblicas de Bolivia y Chile. Este acalorado debate se desplegó en las páginas de dos periódicos rivales de Buenos Aires, "La Nación” y "El Nacional”, entre 1875 y 1877, lo que dio 
al asunto una dimensión nacional. Los argumentos, provenientes de la legislación colonial española, contraponían las posiciones que postulaban una continuidad entre la encomienda y la propiedad de la tierra y aquellas que separaban jurídicamente a ambas. El contexto inmediatamente previo a la disputa fue un violento levantamiento de los campesinos indígenas de la puna en contra de los terratenientes, cuyo origen estaba en un fuerte cuestionamiento de los títulos de propiedad de la ex-encomienda, para ellos ilegítimos. Finalmente intervino la Suprema Corte de Justicia, que en 1877 sentenció que la propiedad de la hacienda pasara a la provincia de Jujuy al avalar la postura de que la encomienda no otorgaba propiedad de la tierra.

La decisión de la Suprema Corte permitió a las autoridades provinciales consolidar su control sobre una vasta área rural, a la par que las proveyó de recursos (por arrendamiento y finalmente venta de tierras fiscales) para financiar sus gastos. En la década de 1890 la provincia desarrolló una política de venta de tierras fiscales que resultó en la reconstitución de las tradicionales haciendas de campesinos arrendatarios en la puna de Jujuy. Sólo en casos de excepcional descontento y actividad política campesina el estado provincial promovió la creación de un sector de campesinos pequeños propietarios, con quienes confiaba garantizar el orden en lejanas zonas fronterizas. Esta estructura agraria se modificaría sólo en la década de 1940 con las reformas introducidas por el primer peronismo.

\section{Campesinos, tierras, arriendos e impuestos}

Los distritos de la puna constituían el caso más notorio de concentración de la propiedad de la tierra en la provincia de Jujuy en el siglo XIX. Eric Boman, un arqueólogo sueco que recorrió la puna hacia 1900, describe acertadamente la situación de la tenencia de tierras en esa zona. La puna -dice Boman-

"está dividida entre un pequeño número de propietarios, de los que casi todos habitan en la ciudad de Jujuy. Cada propiedad tiene una enorme extensión y está poblada por una o varias centenas de indios que deben dar al propietario la mayor parte del producto de sus rebaños y, además proveerles su trabajo personal cuando ellos lo requieran. La mayor parte de los propietarios no han visitado jamás sus dominios de la Puna; ellos se contentan con enviar periódicamente un encargado para requerir los arriendos y resolver los litigios que pudieran surgir entre los indios". ${ }^{1}$

1 Boman, Eric: Antiquités de la région Andine de la Republique Argentine et du Desert d'Atacama, Imprimerie Nationale, Paris, 1908, II, pág. 472. 
Esta situación no había cambiado en absoluto a lo largo del siglo XIX: una decena de grandes propietarios monopolizaba la propiedad de la tierra. Entre ellos el más importante era Fernando Campero, heredero del ex marquesado del valle de Tojo (Bolivia), propietario de varias grandes fincas en la puna de Jujuy. Entre ellas se destacaban la finca Cochinoca y Casabindo, que abarcaba la totalidad del departamento de Cochinoca, y la de Yavi que, con una extensión de 100.000 hectáreas y valuada en 50.000 pesos, comprendía la mayor parte de las tierras del distrito homónimo. En los otros curatos de la puna (Rinconada, Santa Catalina) dos o tres terratenientes se repartían la totalidad de las tierras. (Cuadro I)

\section{CUADRO I}

PROPIEDADES RURALES Y PROPIETARIOS EN LA PUNA, 1860

\begin{tabular}{|c|c|c|c|}
\hline Departamento & Propietario & Propiedad & $\operatorname{Valor}(\$ B)$ \\
\hline Cochinoca & Fernando Campero & $\begin{array}{l}\text { Cochinoca } \\
\text { y Casabindo }\end{array}$ & $?$ \\
\hline \multirow[t]{3}{*}{ Rinconada } & Candelaria Bárcena & Rinconada & 9.012 \\
\hline & Sra. Torres & Oros y Merco* & 2.569 \\
\hline & Pastora Ramos & $\begin{array}{l}\text { San Juan, San León } \\
\text { y Granadas* }\end{array}$ & 3.000 \\
\hline \multirow[t]{4}{*}{ Santa Catalina } & Fernando Campero & Yoscaba & $?$ \\
\hline & José M.Apaza & Cienega? & 700 \\
\hline & Wayar y Aramayo & Santa Catalina & ? \\
\hline & A. Marquiegui & Tafna y Toquero & ? \\
\hline \multirow[t]{5}{*}{ Yavi } & Fernando Campero & Yavi & 50.000 \\
\hline & José F.Quispe & Quiaca & 1.000 \\
\hline & Celedonio Bargas & Rodeo & 225 \\
\hline & Antolín Alvarado & $?$ & 150 \\
\hline & A. Marquiegui & Cerrillos & ? \\
\hline
\end{tabular}

Con la excepción de unos pocos comerciantes y mineros, los casi 12.000 habitantes de la puna eran arrendatarios ("arrenderos" se les llama- 
ba localmente) que pagaban renta a los propietarios de las tierras quienes, por lo general, vivían en Jujuy (en el caso de Campero en Tarija, Bolivia).

Las fincas estaban divididas en parcelas ocupadas por familias campesinas que las aplicaban al pastoreo de sus ganados (sobre todo ovejas y burros, y unas pocas vacas) y subsidiariamente a sus cultivos (maíz, quinoa, papa, alfalfa). Los arrenderos pagaban una renta anual en dinero y a veces en trabajo (conocida como "arriendos y pastajes" o "arriendo y obligaciones") a los propietarios de las fincas por el uso de esas parcelas, calculada de acuerdo con el número de cabezas de ganado y los cultivos que poseían cada uno de ellos. Los administradores cobraban los arriendos dos veces al año, en junio y en diciembre, pero además éstas aumentaron a mediados de la década de 1850, cuando la provincia fijó un impuesto a la propiedad inmueble (llamado "contribución territorial") pagado por los propietarios. Este gravamen del 5 por mil sobre el valor fiscal de la propiedad fue trasladado por los dueños al costo del arriendo. ${ }^{2}$

Además de los arriendos los campesinos puneños pagaban al estado provincial desde 1855 un impuesto llamado "contribución mobiliar", por el que se cobraba a cada familia un $5 \%$ sobre las crías y las cosechas anuales (por eso era llamado localmente "medio diezmo"). El impuesto se aportaba en dinero o en especie y los métodos de cobro eran dos: la presentación voluntaria por el campesino o el recuento de ganado y cultivos que organizaba el cobrador. El estado delegaba la recaudación de este impuesto en particulares, quienes generalmente eran los comerciantes asentados en las cabeceras de los departamentos que, a la vez, actuaban como autoridades locales, jueces de paz y comisionados municipales. Este sistema de tax farming daba lugar a múltiples abusos, frecuentemente denunciados a las autoridades provinciales por los campesinos. ${ }^{3}$

\section{La cuestión de las tierras y la rebelión campesina (1872-1875)}

Desde comienzos de la década del 1870 las tensiones entre campesinos y élites locales derivaron en un conflicto más complejo y profundo.

2 Un estudio detallado de la tenencia de tierra, los arriendos e impuestos en la puna de Jujuy a mediados del siglo XIX se encuentra en Madrazo, Guillermo: Hacienda y encomienda en los Andes. La Puna de Jujuy bajo el marquesado de Tojo, siglos XVII-XIX, Buenos Aires, Fondo Editorial, 1982, y Paz, Gustavo L.: "Resistencia y rebelión campesina en la puna de Jujuy, 1850-1875", Boletín del Instituto de Historia Argentina y Americana 'Dr. Emilio Ravignani', III-4, Buenos Aires, 1991, págs. 43-68.

3 Estudio estas protestas en Paz, "Resistencia y rebelión...”, págs. 43-58. 
Hasta entonces las protestas rurales se alzaban contra los abusos cometidos en la recaudación de impuestos o en un excesivo cobro de arriendos. A partir de este momento los campesinos comenzaron a poner en entredicho la legitimidad de la propiedad de las tierras de la puna. ${ }^{4}$

Esta cuestión fue planteada a fines de 1872 mediante una denuncia presentada ante el gobernador de la provincia por arrenderos de la finca Cochinoca y Casabindo. En ella sostanían que esas tierras estaban ilegítimamente en manos de la familia Campero, herederos de los marqueses de Tojo, quienes no contaban con los debidos títulos de propiedad. Publicaciones periódicas locales recordaban que el "marqués", como todavía se le llamaba, era el ciudadano boliviano que había liderado la invasión boliviana a la puna de Jujuy durante la guerra con la Confederación Peruano-Boliviana (1837-1839). El gobierno provincial acogió favorablemente la denuncia y, en definitiva, decidió traspasar la propiedad de estas fincas a la esfera provincial por decreto, luego de comprobar la endeblez de los títulos de propiedad de Fernando Campero.

Esta decisión oficial, y el éxito de la demanda campesina, impulsó a los arrenderos de otras fincas de la puna a denunciar a su vez las tierras que habitaban como fiscales, al mismo tiempo que mostraban una marcada renuencia al pago de los arriendos a sus propietarios. Durante 1873 la protesta se manifestó con una creciente violencia en toda la puna, en particular en Yavi, donde los campesinos sitiaron el pueblo cabecera del departamento en dos oportunidades, con el fin de que su denuncia por esas tierras se hiciera efectiva. No es vano recordar que Yavi era la hacienda más extensa y rica de la puna jujeña, propiedad también de la familia Campero. El pueblo de Yavi era sede de las autoridades locales y de la casa de la hacienda a la vez, y la principal autoridad del departamento cumplía al mismo tiempo la función de administrador de la finca. El sitio del pueblo por los campesinos significaba no sólo una presión a las autoridades sino sobre todo constituía un abierto desafío al propietario de la hacienda y al odiado y cada vez más oneroso sistema de arriendos.

Durante la primera mitad de 1874 se hizo evidente que las autoridades provinciales no podían controlar a los habitantes de los distritos rurales

4 El relato sobre la rebelión campesina está basado en Rutledge, Ian: "The Indian Peasant Rebellion in the Highlands of Northern Argentina, 1872-1975", The Journal of Peasant Studies, IV-2, 1977, págs. 227-237; Madrazo, Hacienda y encomienda en los Andes..., págs. 164-176; Bernal, Irma: Rebeliones indígenas en la Puna, Búsqueda-Yuchan, Buenos Aires, 1984 y sobre todo en Paz, "Resistencia y rebelión...", págs. 77-99. 
de la puna. Las cabeceras de los Departamentos estaban aisladas en un medio rural hostil, recorrido por bandas armadas de campesinos que se enfrentaban en esporádicas escaramuzas con las escasas patrullas militares enviadas por el gobierno de la provincia en ayuda de esas poblaciones.

La rebelión abierta estalló a mediados de año cuando, ante un cambio político en la provincia — resultado de una lucha electoral nacional entre facciones rivales que apoyaban a los dos candidatos presidenciales Bartolomé Mitre, del partido Nacionalista, y Nicolás Avellaneda, del pacto Autonomista Nacional-, el nuevo gobernador, José María Álvarez Prado, decretó la restitución de la finca Cochinoca y Casabindo a la familia Campero el 3 de julio de 1874. De todos modos, por ese mismo acto la provincia se reservaba el derecho de pleitear la definitiva propiedad de esas tierras ante la Suprema Corte de Justicia de la Nación en Buenos Aires.

La restitución de las tierras desencadenó la fulminante expansión de la rebelión campesina por toda la puna, a la cual se sumaron algunos personajes de la élite local puneña enemistados con la nueva situación política provincial. Entre ellos, Laureano Saravia eslabonó una alianza con los líderes del movimiento campesino. Hacia fines de 1874 Saravia conducía la rebelión, dándole a ese movimiento una cohesión y fuerza mayor de la que había tenido hasta ese momento. Los rebeldes lograron ocupar casi todos los distritos de la puna y hacerse fuertes en los pueblos cabeceras de los departamentos, de donde la escasa población blanco-mestiza huía horrorizada.

El choque final con las milicias provinciales, reforzadas con un destacamento enviado por el gobierno nacional desde la vecina provincia de Salta, se produjo en las serranías de Quera el 4 de enero de 1875, siendo los campesinos completamente derrotados por las tropas regulares. Inmediatamente después de la batalla las autoridades provinciales y los terratenientes comenzaron la tarea de imponer nuevamente el orden en la puna.

\section{La disputa sobre la encomienda y la expansión de la jurisdicción estatal}

Poco después de Quera se produjo un feroz debate jurídico, histórico y político sobre la naturaleza, características y alcances de la encomienda y su relación con las tierras sobre las que se asentaba. Esta controversia se remontaba a la vieja cuestión colonial acerca del derecho que los encomen- 
deros tenían sobre las tierras donde se ubicaba la encomienda, pero en realidad lo que estaba en juego era la propiedad de las fincas puneñas de Cochinoca y Casabindo. El debate se entabló en las páginas de tres prestigiosos periódicos porteños - "La Nación, "El Nacional" y "La Prensa"y luego también ante la Suprema Corte de Justicia en Buenos Aires.

El derecho de propiedad de Fernando Campero había sido cuestionado por las administraciones provinciales de Pedro J. Portal y de Teófilo Sánchez de Bustamante desde 1872, y desafiado violentamente por los campesinos de la puna entre 1872 y 1875 . Los constantes reclamos de Fernando Campero se habían coronado en la restauración de sus derechos por el nuevo gobierno provincial de José María Álvarez Prado, en virtud del decreto del 3 de julio de 1874 .

El citado decreto de restauración había reservado a la provincia el derecho de iniciar acciones legales ante la Suprema Corte de Justicia para establecer con certeza los derechos de propiedad sobre Cochinoca y Casabindo. De acuerdo con la Constitución de 1853, el caso caía bajo la jurisdicción federal ya que las dos partes involucradas eran una provincia (Jujuy) y un ciudadano extranjero (Campero era boliviano).

La cuestión de las tierras de la puna había adquirido, por tanto, un marcado cariz político. Los seguidores del depuesto gobernador mitrista Sánchez de Bustamante alegaban que su rival, el avellanedista Álvarez Prado, había revocado las medidas previas tomadas respecto de Cochinoca y Casabindo, restituyéndoselas a Campero como recompensa por el "efectivo apoyo" que éste había prestado en el derrocamiento del gobierno anterior. Las acusaciones de los mitristas depuestos llegaban aun más lejos: el abogado de Campero, el boliviano Eugenio Caballero, era el redactor del decreto del 3 de julio y quien lo había entregado al gobernador para su publicación. El reconocimiento provincial del derecho de propiedad de Campero sobre las fincas de la puna creaba las bases para futuros reclamos legales. Los seguidores de Bustamante acusaban al gobierno provincial de haber mantenido reuniones secretas con Campero y su abogado conducentes a iniciar acciones legales ante la Suprema Corte de Justicia, con el fin de llegar a un arreglo entre las partes por medio del cual la provincia renunciaría a la propiedad de las tierras a cambio de una suma de dinero otorgada por Campero, quien recibiría los títulos de propiedad definitiva. ${ }^{5}$

5 Sánchez de Bustamante, Jose: Cuestión ruidosa. El gobierno de la Provincia de Jujuy con el ciudadano boliviano Fernando Campero sobre reivindicación. Colección de artículos publicados en “La Nación” y “El Nacional”, Buenos Aires, La Nación, 1877, págs. 107-108, 139. 
El 12 de julio de 1875 la legislatura de Jujuy autorizaba al gobernador Álvarez Prado a designar un apoderado de la provincia ante la Suprema Corte de Justicia, y a erogar 5.000 pesos bolivianos para cubrir los gastos generados por el juicio. Al día siguiente el gobernador nombró a su suegro y factotum político José Benito Bárcena como apoderado ante la Corte. La provincia inició el juicio reluctantemente en febrero de 1876, después de que la transacción extra-judicial con Campero fallara al haber sido denunciada por los mitristas.

A lo largo de 1876 se desarrolló un abrasivo debate. De un lado el abogado Caballero - un escritor verdaderamente prolífico - representaba la posición de Campero publicando tres panfletos que reunían los artículos aparecidos en el periódico pro-autonomista "El Nacional"; del otro lado José Sánchez de Bustamante (sobrino del gobernador depuesto y su delfín político) publicó una larga colección de artículos escritos originalmente para el diario mitrista "La Nación" y en el independiente pero favorable a Mitre "La Prensa". El debate era un verdadero contrapunto ya que no bien una parte publicaba un artículo en su periódico, la otra respondía con otro en un par de días. Ambos lados se atacaban con una mezcla de información más o menos fidedigna, provocaciones políticas y golpes bajos personales en un apasionado y vitriólico intercambio.

El tema en debate era la propiedad de las tierras de la puna pero la naturaleza del régimen de encomienda era central a la contienda, ya que la principal cuestión era si la encomienda implicaba propiedad de la tierra o no. El asunto tenía dos lados interrelacionados: legal e histórico. El lado legal ponía en entredicho si la encomienda era una institución meramente administrativa y por lo tanto posible de modificaciones por medio de decisiones tomadas por el poder ejecutivo, o si por el contrario pertenecía al derecho civil y debía ser tratada como una cuestión privada, afectada únicamente por decisiones judiciales. El lado histórico de la controversia tenía que ver con la manera como los antepasados de Campero habían obtenido la encomienda en el periodo colonial. Como la familia Campero compró los derechos a la encomienda de Cochinoca y Casabindo a perpetuidad en 1705, Fernando Campero consideraba que la tierra de la ex-encomienda le pertenecía por derecho de compra. Por el contrario, sus opositores pensaban que la concesión había caducado con la abolición de las encomiendas en 1813 y que, de todos modos nunca incluyó la propiedad de la tierra. Viejos documentos coloniales y las Leyes de Indias fueron ampliamente citados por la dos partes para sustentar sus contradictorias posiciones. 
El comienzo de ambos argumentos era el controvertido decreto del gobernador Pedro Portal de 1872, que declaraba propiedades fiscales a las tierras de Cochinoca y Casabindo luego de constatar que Fernando Campero no contaba con los títulos de propiedad. Ese decreto se basaba en el argumento de que la encomienda no suponía la propiedad de las tierras sino solamente el derecho del encomendero a recolectar el tributo de los indígenas a cambio de adoctrinamiento en la fe y su protección. Los indígenas continuaban teniendo el "dominio útil" de las tierras donde se asentaba la encomienda y la Corona era la propietaria de las mismas. En consecuencia, luego de la independencia la propiedad de las tierras revertía a la provincia. Esta doctrina legal consideraba a la encomienda como una mera institución administrativa que de ninguna manera afectaba los derechos civiles del encomendero, en este caso la familia Campero. Como nunca habían sido dueños de la tierra, el gobierno no veía necesario recurrir a la justicia para hacer valer sus derechos de legítimo propietario por reversión, lo que afirmó por un acto del poder ejecutivo (el decreto del 3 de julio de 1874).

Esta postura legal fue respondida por el abogado de Campero, quien apeló en primer término a la historia para resolver la cuestión. En 1874 Caballero publicó un folleto que reproducía los documentos por los que la Corona había otorgado a los Campero la encomienda de Cochinoca y Casabindo. El 25 de junio de 1705 el rey Felipe V había concedido a Juan Manuel Fernández Campero dicha encomienda y el título de marqués del Valle de Tojo "para si y para sus herederos a perpetuidad", a cambio de un pago de 16.000 escudos de plata para garantizar la posesión. El documento real otorgaba a Campero el derecho de "propiedad y pleno dominio" sobre la encomienda y estipulaba que podía disponer de ella como lo haría con cualquiera de sus otras posesiones. Caballero recordaba que Campero había sucedido a su suegro como beneficiario de la encomienda, lo que le convertía en el segundo encomendero. Por lo tanto la real cédula de 1705 no podía sino otorgarle la propiedad de las tierras donde se asentaba la encomienda de Cochinoca y Casabindo puesto que el beneficio de los tributos de los indígenas lo gozaba ya por herencia. El abogado también agregaba que cuando la Corona decidió incorporar las encomiendas del Tucumán a la jurisdicción real a mediados del siglo XVIII, la de Campero había sido exceptuada en virtud de sus derechos de propiedad adquiridos. ${ }^{6}$

6 Caballero, Eugenio: Réplica de Eugenio Caballero en la cuestión ruidosa, Buenos Aires, "El Nacional”, 1876, págs. 79-84; también [Miguel Alviña], Causa célebre. Atentado de gobernadores contra la propiedad del ciudadano, Salta, La Discusión, 1874, págs. 19-27. 
Caballero refutó el decreto de 1872 tambien en base a argumentos legales ya que contenía una "interpretación violenta, pasional e irracional del término encomienda". Apoyándose en una peculiar lectura de las Leyes de Indias, el abogado afirmaba que el término tenía dos significados, uno administrativo y el otro territorial. El primero era el que había sido considerado y aplicado por el gobierno de Jujuy en el decreto de 1872 pero, insistía el abogado, era improcedente en el caso de Cochinoca y Casabindo desde el momento que, según su ya comentada interpretación, la Corona había concedido a Campero las tierras y no la jurisdicción en 1705. Y como la encomienda era una institución de derecho civil, por la figura de continuidad jurídica de los estados, su estatus de propiedad privada no podía ser alterado por un decreto administrativo.

Caballero reforzó su defensa de los derechos de propiedad de Campero con el significado territorial de la encomienda. De acuerdo con esta posición, el término "encomienda" implicaba la concesión del tributo indígena al encomendero junto con el territorio donde se establecía la encomienda. Para sustentar este argumento Caballero recurrió a la figura retórica de la metonimia. Desde su otorgamiento por cédula real de 1705 las tierras fueron llamadas "Cochinoca y Casabindo", creando de esa manera un vínculo indivisible entre territorio y jurisdicción por el cual

"el territorio le dio a la encomienda su nombre de Casabindo y Cochinoca y a su vez el territorio de Casabindo y Cochinoca toma su nombre de la encomienda de acuerdo con la jurisdicción que sobre tierra e indios le otorga la encomienda. Este modo de indicar al mismo tiempo el territorio y la jurisdicción es común a todas las lenguas del mundo por medio de una figura gramática llamada metonimia por la cual el continente es expresado por el contenido y viceversa"?

De estas disquisiciones retóricas Caballero concluía que los derechos de propiedad de Campero eran sólidos. La real cedula de 1705 le había otorgado la encomienda en perpetuidad, lo que indudablemente (por la figura de metonimia) significaba tanto la jurisdicción sobre los indios como el territorio donde estaba establecida. El decreto del gobernador Portal constituyó un abuso de poder contra un ciudadano pacífico, que sólo respondía a los intereses políticos de quien lo dictó, aplicando una doctrina legal completamente equivocada. La provincia de Jujuy había cometido un serio crimen al despojar a un ciudadano de su propiedad. Sólo en un lugar como Jujuy — decía Caballero- - tan alejado de los vientos de renovación política que soplaban

7 Caballero, Réplica..., págs. 44. 
desde Buenos Aires y gobernado por una oligarquía despreciativa de toda legalidad, podía concebirse una afrenta al derecho de estas promociones. $\mathrm{La}$ situación había cambiado, agregaba incisivamente, después de que la familia que había detentado el poder en la provincia por más de veinte años (en obvia referencia a los Sánchez de Bustamante) fuera desplazada del poder. ${ }^{8}$

La respuesta de Sánchez de Bustamante no se hizo esperar. Se basaba, como la de su oponente, en argumentos históricos y legales. En primer término Campero no había aportado ninguna prueba documental que sustentara su derecho de propiedad sobre las tierras en cuestión. Caballero publicaba la real cédula concediendo a Campero la encomienda pero no había presentado el original a las autoridades ni tampoco el documento clave origen de toda la disputa: el título de propiedad de las tierras.

Bustamante recurrió a la autoridad de las Leyes de Indias para apoyar el punto fundamental de su defensa alegando que las leyes coloniales separaban muy claramente las esferas de la encomienda y la propiedad de la tierra. El Libro IV, Títulos 8, 9 y 12 de la Recopilación de Leyes de Indias estipulaba que la encomienda no otorgaba propiedad de las tierras donde había sido concedida y por lo tanto no engendraba ningún derecho sobre las mismas. La encomienda involucraba sólo el usufructo de los tributos de los indígenas dentro de los límites fijados por las leyes y los términos de la concesión real. Los límites eran muy claros: los indios gozaban del "dominio útil" de las tierras donde se establecían las encomiendas de las que la Corona era propietaria.

La Corona, recordaba Bustamante, otorgaba tierras mediante otro tipo de documento, las "mercedes de tierras", que mencionaban explícitamente los límites de las mismas. Casi todas las haciendas de Jujuy se habían originado como "mercedes reales" durante la colonia, y el gobierno provincial aceptaba estos documentos como legítimos títulos de propiedad. En su lectura de la real cédula de 1705 Bustamante establecía que la Corona había otorgado a los Campero la posesión de la encomienda pero no la de la tierra. El documento difería de una "merced" en que no proveía detalles sobre los límites territoriales de la concesión sino sólo los nombres de las ubicaciones de los grupos indígenas encomendados. ${ }^{9}$

8 Estudio el predominio y caída de la familia Sánchez de Bustamante en Jujuy en Paz, Gustavo L.: "El gobierno de los 'conspicuos': familia y poder en Jujuy, 1853-1875”, en Sabato, Hilda y Lettieri, Alberto (compiladores): La vida política en la Argentina del siglo XIX. Armas, votos y voces, Fondo de Cultura Económica, Buenos Aires, 2003, págs. 223-241.

9 Sánchez de Bustamante, Cuestión ruidosa..., págs. 122, 142-143. 
Bustamante recordaba a su oponente que Fernández Campero se había convertido en encomendero mediante su matrimonio con Clemencia de Ovando (heredera del encomendero original), quien había muerto poco después. De este modo se justificaba la cuantiosa suma pagada por Campero para conseguir la confirmación de sus derechos a la encomienda por medio de matrimonio y herencia. Agregaba también que el hecho de que la Corona les hubiera concedido la encomienda a perpetuidad - y no por una o dos vidas como era costumbre - era una rareza, debida sin duda a que Campero había pagado 16.000 ducados de plata por ella. El pago, por lo tanto, no se equiparaba a una compra como Caballero sostenía sino que constituía una compensación por las concesiones de la corona. Bustamante concluía que

si la Cedula [de 1705] no cambió, como no podía hacerlo, la naturaleza de la concesion de la encomienda, y como la tierra no era parte de esta concesión, queda completamente claro que no podía haber propiedad establecida sobre ellas sino sólo sobre la encomienda misma, es decir el derecho de recaudar el tributo de los indios de los dichos pueblos. ${ }^{10}$

Por lo tanto, aplicando el principio de continuidad jurídica de los estados invocado por Caballero en sus escritos, Bustamante razonaba que la naturaleza de la concesión original de la encomienda no había cambiado en el tiempo: como no había incluido la propiedad de la tierra en la concesión original tampoco la incluía después de la independencia. Concluía lógicamente que, al ser la encomienda una institución administrativa, era pasible de ser modificada por un acto del poder ejecutivo.

De esta manera, de acuerdo con Bustamante, el decreto del gobernador Portal de 1872 estaba justificado por la ley y por la historia. Pero también aducía razones políticas para su conveniencia. Primero, el decreto de traspaso de Cochinoca y Casabindo al fisco redundaba en un beneficio para la provincia ya que los arriendos pagados por los campesinos al terrateniente pasarían a engrosar las rentas del estado provincial. Segundo, como las fincas en disputa limitaban con Bolivia y eran "reclamadas por un ciudadano boliviano" (que había tenido una actitud hostil a la provincia en la guerra contra la Confederación Peruano-Boliviana de fines de la década de 1830), su incorporación consolidaría la "integridad territorial" de la provincia amenazada hasta entonces por los reclamos de Campero. ${ }^{11}$

10 Ibidem, págs. 144-145.

11 Ibidem, págs. 87,94. 
La Suprema Corte de Justicia comenzó a tratar el asunto a comienzos de 1876. Ambas partes presentaron su caso por medio de sus apoderados. Caballero insistió en su posición de que la encomienda implicaba propiedad de la tierra basada en su peculiar lectura de las Leyes de Indias y en su uso de la figura retórica de metonimia. Los derechos de Fernando Campero a las tierras eran tres: la Corona española se las había concedido en "merced a perpetuidad" a sus ancestros, por la que pagaron una considerable suma; había recibido esas tierras en herencia; todo reclamo del estado sobre las tierras había dejado de existir luego de 150 años de posesión ininterrumpida por parte de su familia. Al haber fracasado la negociación con Campero, el abogado de la provincia, Francisco Uriburu (pariente del gobernador Álvarez Prado y del apoderado anterior, Bárcena), hizo suyos los argumentos legales contrarios: separación de la encomienda y propiedad de las tierras, y reversión de las propiedades de la Corona a la provincia después de la independencia. ${ }^{12}$

La Suprema Corte llegó a una decisión a comienzos de 1877. La sentencia apoyaba el reclamo de la provincia y le otorgaba la propiedad indiscutida de las tierras de Cochinoca y Casabindo. En sus fundamentos la Corte declaraba que

ni el acusado Fernando Campero ni sus ancestros habían ejercido derechos de propiedad sobre los territorios ocupados por los pueblos de Cochinoca y Casavindo [sic]; que los mismos no han podido prescribir ya que no están sujetos a prescripción; que el sistema de encomiendas se había extinguido como incompatible con el régimen político de la República; y que la Provincia de Jujuy goza y siempre ha gozado de la propiedad y jurisdicción sobre los territorios en disputa, teniendo total poder para disponer de ellos como considere conveniente para el Pueblo de la Provincia. ${ }^{13}$

La sentencia de la corte suprema combinaba consideraciones legales, históricas y políticas. La Corte apoyó la posición legal de la provincia (sostenida por Sánchez de Bustamante en la polémica) de que las encomiendas eran instituciones administrativas y no otorgaban propiedad de las tierras sobre las que eran establecidas. En este sentido el decreto provincial de

12 Caballero, Réplica..., págs. 66-87.

13 "Causa XLIV-1877, La Provincia de Jujuy contra D. Fernando Campero, sobre reivindicación”, en Fallos de la Suprema Corte de Justicia Nacional con la relación de sus respectivas causas, Buenos Aires, Coni, 1878, Tomo décimo, págs. 29-40; la cita de pág. 40. La sentencia fue republicada en Sánchez de Bustamante, José: Fallo de la Suprema Corte Federal en el litis de la Provincia de Jujuy con el Sr. D. Fernando Campero, sobre las tierras de Cochinoca y Casabindo. A mis comprovincianos, La Nación, Buenos Aires, 1877. 
1872 que transfirió la propiedad de Cochinoca y Casabindo a la provincia era una acción legal correcta según derecho, tomada por el estado en beneficio del pueblo de la provincia. La historia estaba también en contra de Campero. La Corte recordaba que las encomiendas eran incompatibles con el sistema republicano de gobierno y que habían sido abolidas por la Asamblea del año 1813.

No sólo las encomiendas eran una institución anticuada que no correspondía a una nación republicana moderna como la Argentina sino que, en el caso particular de Cochinoca y Casabindo, la sentencia de la Corte Suprema refleja el objetivo del Estado nacional de establecer y controlar su territorio y sus fronteras. El hecho de que las tierras en cuestión limitaran con Bolivia y de que Fernando Campero fuese un ciudadano boliviano residente en Bolivia tuvo peso en la decisión de la Corte. Su sentencia consolidaba la soberanía de Jujuy sobre un territorio fronterizo reclamado por un extranjero. ${ }^{14}$

La sentencia de la Suprema Corte de Justicia tuvo, por lo tanto, muchos significados. Para la provincia de Jujuy fue una afirmación de su soberanía sobre un vasto territorio que hasta entonces escapaba a su control. Le otorgó a la provincia la posibilidad de recaudar los arriendos, de beneficiarse con la eventual venta de las tierras (como ocurrirá en la década de 1890) y de ejercer un mayor control sobre la población rural de la puna, que se había mostrado renuente a obedecer a las autoridades desde 1872. Para los terratenientes la sentencia implicaba la restauración del orden en la campaña de Jujuy al delimitar el derecho de propiedad y poner fin al cuestionamiento por parte de los campesinos. Esto les permitía retomar el cobro de los arriendos legalmente a pesar de la resistencia de los campesinos indígenas. Para estos la sentencia revestía una importancia fundamental. Les daba una oportunidad de satisfacer sus deseos de acceder a la propiedad de la tierra mediante una eventual compra de parcelas al estado. Mientras tanto seguían con sus tradicionales peticiones al gobernador, toda vez que oficiales estatales y notables locales abusaran de su poder, y pagaban el arriendo a un estado menos demandante que el odiado terrateniente a quien, gracias a la inesperada ayuda de la Suprema Corte, se habían sacado de encima.

14 Ver los comentarios a la sentencia de la Corte Suprema en Portal, Pedro J. y Sánchez de Bustamante, Teófilo: Nuestra Justificación. Sentencia de la Suprema Corte Federal en la cuestión de la Provincia de Jujuy con D. Fernando Campero sobre Casabindo y Cochinoca con otros antecedentes, Salta, 1877. 


\section{Campesinos, Estado y orden rural (1877-1900)}

A partir de la sentencia de la Corte Suprema de Justicia, el Estado provincial fue el árbitro en cuanto a las posibilidades de acceso de los campesinos a la propiedad de la tierra en vastos sectores de la puna de Jujuy. Desde entonces el estado comenzó a desarrollar una política de tierras en la puna, con aplicación de decisiones diferentes en cuanto se refiere a tierras privadas o tierras públicas que apuntaban a la consolidación del orden en las zonas rurales y la obtención de recursos para el erario provincial.

Conocida la sentencia judicial, la Legislatura provincial debatió dos posiciones con respecto al destino de las tierras fiscales de Cochinoca y Casabindo. La primera sostenía la conveniencia del deslinde y subdivisión de las tierras, y su posterior venta. Un proyecto de ley de agosto de 1877 establecía la división de las tierras en "rodeos" y su posterior tasación y venta a sus ocupantes. El proyecto fomentaba la compra por los ocupantes mediante un subsidio fiscal: los residentes compradores pagaban al fisco un canon por el usufructo de las tierras de la mitad de lo que debían pagar quienes no participaban de la compra. Este arriendo se reducía al ritmo del pago de las cuotas: el $50 \%$ al pago de la mitad de la deuda y en su totalidad a la cancelación definitiva. Este proyecto, con escasas modificaciones, fue convertido en ley provincial en marzo de $1879 .{ }^{15}$

Un año después, una nueva Legislatura derogó esa ley y la reemplazó por otra que sostenía la conveniencia de la conservación de las tierras fiscales de la puna en la esfera fiscal, a la vez que estipulaba que los arriendos pagados al Estado por sus ocupantes formaban parte de las rentas provinciales. La ley preveía el deslinde definitivo de las tierras, a fin de determinar sus verdaderos límites. Los arriendos se cobraron a partir de 1880 mediante un sistema de recaudadores designados por el Estado, residentes en el pueblo de Cochinoca y sus pendientes en los distritos rurales. ${ }^{16}$

A comienzos de la década de 1880 los campesinos de la puna comenzaron a reclamar el deslinde de Cochinoca y Casabindo. En la base de estas solicitudes elevadas al gobierno provincial se hallaba la presunción y el deseo de que los territorios fiscales se extendieran más allá del departamen-

15 Archivo de la Legislatura de Jujuy (ALJ), Carpeta 33. Proyecto de ley, 20-8-1877; ALJ, Carpeta 33, Ley del 19-3-1879. Las diferencias con el Proyecto de ley de 1877 residían en el valor de cada sección, no especificadas en la ley, y en la posibilidad que ésta ofrece del otorgamiento del título de propiedad con la cancelación del $50 \%$ del valor de la compra.

16 ALJ, Carpeta 33, Ley 12-3-1880. 
to de Cochinoca y poder remover a los terratenientes que ocuparan indebidamente tierras fiscales. Esta estrategia no dio resultados positivos pues el gobierno desconoció las notas de protesta de los campesinos. Hacia 1885 esas tierras seguían aún sin deslindar, y el resto de las haciendas de la puna en manos de sus tradicionales propietarios. ${ }^{17}$

A partir de 1890 la política gubernamental de tierras fiscales se orientó hacia la venta de las mismas a consecuencia de la crisis financiera desatada en Argentina. La provincia de Jujuy, que era fuertemente subsidiada por el gobierno nacional, se encontró repentinamente sin recursos. La venta de tierras fiscales fue una de las medidas encaradas por las administraciones provinciales para cubrir el déficit. Entre 1891 y 1893 la administración provincial formuló el marco legal que reguló la enajenación de las tierras fiscales de la puna. En 1892 fue practicado el deslinde de las tierras fiscales y su división en secciones o rodeos. La ley de 1891 daba prioridad a los arrenderos en la compra de las tierras pero el decreto de 1893 introducía una cláusula por la cual los campesinos serían favorecidos sólo en caso de una igualdad de ofertas. De esta manera la venta de tierras fiscales de la puna promovió la restauración de las haciendas de propiedad privada con campesinos arrenderos a fines del siglo XIX. ${ }^{18}$

Las haciendas de propiedad privada conservaron su territorio y el sistema de arriendos intacto. El estado provincial no siguió una política de tierras activa con respecto a ellas, con la excepción de dos casos en los que impulsó la venta a los arrenderos ocupantes. El objetivo de esta infrecuente política lo puso de manifiesto el gobernador Eugenio Tello en su mensaje a la Legislatura provincial de enero de 1884. A su regreso de una larga recorrida por la puna en 1883 el gobernador observaba:

Sabeis y consta en documentos que hasta el día en que me encargué del Gobierno, el derecho de propiedad era desconocido en gran parte de la Puna y Quebrada. Como sobre ese derecho reposa el orden social, el constitucional, resultaba que desapareciendo aquel, esta provincia no estaba en condiciones de Estado Confederado...Puedo decir, que hemos salvado el naufragio, porque ahora los indígenas están sometidos, reconocen el derecho de propiedad, respetan el principio de autoridad...Pero para terminar la obra, es indispensable convertir en propietarios a los ciudadanos indígenas de Valle Grande y Yoscaba. Allí por la situación geográfica no es posible hacer sentir fácilmente la acción de la autoridad...haciéndolos propietarios serán guardianes del orden. ${ }^{19}$

17 Estudié este asunto con detalle en Paz, Gustavo L.: "Tierra y resistencia campesina en la puna de Jujuy, 1875-1910”, Andes. Antropología e Historia, 6, Salta, 1994, págs. 207-234.

18 Provincia de Jujuy: Compilación de Leyes y Decretos, Buenos Aires, 1907, págs. 286-310.

19 Tello, Eugenio: Mensaje del Gobernador de la Provincia en la apertura de las Sesiones Ordinarias, 1 de enero de 1884, Jujuy, 1884. 
Tanto la hacienda Yoscaba (en el departamento de Santa Catalina) como la de Valle Grande, en el departamento homónimo, eran zonas bastante inaccesibles que hacían extremadamente difícil el control de la población rural. Durante la violencia campesina de comienzos de la década de 1870 los arrenderos de ambas fincas (sobre todo los de Yoscaba) se habían mostrado particularmente hostiles a los terratenientes y agentes estatales y su resistencia a ambos no había cesado con el restablecimiento del orden después de la batalla de Quera. En el caso de Yoscaba se sumaba el hecho de que la hacienda limitaba con Bolivia, lo que facilitaba el contrabando, el acceso a armas y la huida de los rebeldes, como había ocurrido tantas veces antes. El gobernador reconocía que la ausencia de propiedad de la tierra había costado una rebelión e incesantes afrentas a la autoridad de terratenientes y oficiales del gobierno desde 1870. En su mensaje Tello sostenía que la base del orden social descansaba en el reconocimiento y respeto del derecho de propiedad. Sólo si los "ciudadanos indígenas" se convertían en propietarios podían participar plenamente de ese orden y garantizar su custodia. Es por eso que impulsó ante la legislatura la venta de esas fincas a sus arrenderos y su división en parcelas de propiedad privada.

En su viaje por la puna Tello había constatado la voluntad compradora de los arrenderos. Sólo quedaba convencer a los propietarios de la conveniencia de tal venta. La viuda de Campero, Corina Aráoz, decidió vender la finca Yoscaba a resultado de la constante acción campesina que imposibilitaba el cobro de arriendos. El propietario de Valle Grande, Rufino Valle, había fallecido recientemente y sus herederos recibieron favorablemente la oferta del gobierno.

Las haciendas Valle Grande y Yoscaba fueron vendidas por sus propietarios a los arrenderos muy poco después del mensaje de Tello, con la mediación del Estado. Yoscaba fue adquirida por varios de sus arrenderos en 1886 y deslindada en parcelas de propiedad privada en 1903. Valle Grande siguió el mismo proceso en $1887 .{ }^{20}$

Analicemos el proceso de venta de Yoscaba con detalle. Los campesinos se organizaron rápidamente y a mediados de 1885 ya habían nombrado como sus "representantes" a tres de los arrenderos compradores: José María y Eusebio Maidana, y Agustín Gutierrez. Su principal cometido era la recolección de los aportes monetarios de los campesinos para completar el valor de la finca. La "asociación" de arrenderos consiguió efectivizar la

20 Para Yoscaba, Archivo de Catastro (AC), Santa Catalina, Libro I, págs. 50-64. Para Valle Grande, Archivo Histórico de la Provincia de Jujuy (AHPJ), Sección Expedientes, Carpeta I, 409/1885. 
compra a comienzos de octubre de 1886. Con la garantía y respaldo del gobierno provincial los campesinos compradores obtuvieron un crédito de $11.874,41 \$ \mathrm{~m} / \mathrm{n}$ en la Sucursal Jujuy del Banco Nacional. La venta se realizó en $14.000 \$ \mathrm{~m} / \mathrm{n}$, y la hacienda quedó hipotecada hasta la cancelación definitiva de la deuda. José M. Maidana quedó encargado de cerrar esta negociación. ${ }^{21} \mathrm{~A}$ juzgar por su correspondencia privada no fue tarea fácil recolectar las cuotas de los arrenderos compradores debido a la oposición de los notables locales, en su mayoría comerciantes, quienes pugnaban también por el acceso a la propiedad de la tierra. ${ }^{22}$ La hipoteca fue finalmente cancelada en 1903. Poco antes se había procedido al deslinde y división de la finca en parcelas de propiedad privada. ${ }^{23}$

La venta de la hacienda Yoscaba abrió la posibilidad del acceso de exarrendatarios a la propiedad de las tierras y la formación de un sector de campesinos pequeños propietarios que constituyó una excepción a las haciendas con arrenderos de la puna. La protesta campesina continuó hasta mediados del siglo XX sólo en las zonas de tierras fiscales traspasadas a manos privadas y en las tradicionales haciendas con arrenderos mientras que en Yoscaba imperaba la calma. Los "ciudadanos indígenas" propietarios creados por el estado provincial se manifestaron más afectos al orden que algunos de los tradicionales terratenientes y funcionarios locales quienes, a comienzos del siglo XX, todavía abusaban de su poder en el cobro de arriendos e impuestos.

\section{Conclusión}

La sentencia de la Suprema Corte de Justicia le permitió al estado provincial de Jujuy aplicar una política de tierras a fin de obtener recursos mediante el cobro de arriendos y finalmente su enajenación. La venta de tierras fiscales al mejor postor desde 1895 resultó en la reconstitución de las haciendas con arrendatarios en la puna de Jujuy. La mediación estatal a fines de la década de 1880 entre terratenientes y arrendatarios impulsó la venta de dos grandes fincas rurales de propiedad privada ubicadas en luga-

21 AHPJ, Jujuy, 5-9-1885; AC, Santa Catalina, Libro I, págs. 4-10. Ver Archivo de los Tribunales de Jujuy (ATJ), Protocolos Notariales, Escribanía de Melitón González, 1886, T.3, pág. 497v.

22 AHPJ, Documentos Maidana, Carta 11, Pasaje 9-1-1888; Carta 12, Pasaje 26-3-1889.

23 AC, Santa Catalina, Libro I, págs. 50-64. 
res inaccesibles y convirtió a sus ocupantes en campesinos pequeños propietarios. En estos "ciudadanos indígenas" descansaba la estabilidad del orden rural en esas lejanas regiones. Hacia 1900 el estado provincial podía garantizar el orden social en las áreas rurales.

Una situación similar a la de la puna de Jujuy se daba en el mismo momento en el vecino altiplano boliviano. Allí, a fines del siglo XIX, una avanzada liberal en contra de las comunidades indígenas amenazó con la extinción de la propiedad comunal de las tierras. La legislación liberal sobre tierras de los años 1870 — un programa aceptado por todas las facciones de la élite- difería sólo en la metodología de la extinción de las tierras comunales y sus posibles resultados. En este último punto, una facción de la élite abogaba por la consolidación de un campesinado pequeño propietario, tal como ocurrió en el caso argentino en Yoscaba. Otra sostenía que las tierras comunales debían pasar a manos de más eficaces haciendas particulares con colonos, proceso que en la puna argentina había ocurrido durante el período colonial y reafirmado a fines del siglo XIX en virtud de la política provincial de tierras. Esta segunda opción fue la que primó. ${ }^{24}$

La literatura sobre el altiplano boliviano señala dos importantes condiciones que limitaron el éxito del programa liberal de exvinculación de tierras comunales: la resistencia del campesinado indígena y la escasa capacidad del estado boliviano para poner en práctica las leyes. Las estrategias de resistencia desplegadas por los campesinos de las comunidades indígenas ante la legislación liberal pusieron freno a la privatización de las tierras comunales y la expansión de las haciendas a comienzos del siglo XX en torno del lago Titicaca y del norte de Potosí, y al menos canalizaron la reestructuración de la sociedad local de manera que no les resultara tan desfavorable en Chuquisaca. ${ }^{25}$

En cuanto a la capacidad de coerción del Estado, esta fue sin duda más limitada en el caso boliviano que en el argentino. Las autoridades bolivianas encontraron muy difícil la puesta en práctica de la legislación liberal sobre tierras, sobre todo en el altiplano. ${ }^{26}$

24 Langer, Eric: "El liberalismo y la abolición de las comunidad indígena en el siglo XIX", Historia y Cultura, 14, La Paz, 1988, págs. 59-95 (sobre todo págs. 64-75).

25 Rivera, Silvia, "Oprimidos pero no vencidos". Luchas del campesinado aymara y quechwa en Bolivia, 1900-1980, Ginebra, UNRISD, 1986, págs. 13-42; Platt, Tristan, Estado Boliviano y ayllu andino. Tierra y tributo en el Norte de Potosí, Lima, IEP, 1982, págs. 73-132 y Langer, Eric, Economic Change and Rural Resistance in Southern Bolivia, 1880-1930, Stanford University Press, Stanford, 1989 (en particular capítulos 4, 5 y 6).

26 Langer, "El liberalismo y la abolición...", págs. 78-81 y 85-87; Platt, Estado Boliviano y ayllu andino, págs. 94-111. 
En la puna de Jujuy la capacidad de resistencia campesina a la nueva legislación sobre tierras se vio limitada por las características del desarrollo local de la comunidad y del Estado. Por un lado, la comunidad campesina-indígena en el altiplano jujeño presentaba en la segunda mitad del siglo XIX una debilidad mucho mayor que las de sus contrapartes bolivianas. En Jujuy la comunidad como institución jurídica propietaria de tierras había sido suprimida por las autoridades provinciales en la década de 1830; para fines de la década de 1860 las autoridades comunitarias que aún subsistían en la puna fueron suprimidas y reemplazadas por autoridades locales designadas por los jefes departamentales. Por otro lado, la extinción legal de las comunidades en la puna jujeña se corresponde con una creciente presencia del estado provincial y nacional a partir de la segunda mitad de la década de 1860 y con mayor fuerza después de $1880 .{ }^{27}$

A comienzos del siglo XX las condiciones estaban dadas para que la mayoría de los campesinos de la puna de Jujuy se integraran al mercado de trabajo que desde 1880 se estaba ampliando con fuerza en el Noroeste argentino en torno de la industria azucarera. Hacia 1920 los ingenios comenzaron a reclutar al campesinado de la puna como mano de obra estacional iniciando un largo ciclo de migraciones, temporarias al principio y más tarde definitivas, desde la puna a las tierras bajas. Sólo las reformas a los regímenes laborales y la tenencia de tierra introducidas por el peronismo en la década de 1940 quebrarían este ciclo.

27 Sobre la formación del estado nacional en Argentina véase Oszlack, Oscar, La formación del estado argentino, Editorial de Belgrano, Buenos Aires, 1982. Para la presencia del estado (provincial y nacional) en las áreas rurales de la provincia de Jujuy véase mi tesis doctoral Paz, Gustavo L., Province and Nation in Northern Argentina. Peasants, Elite and the State, 1780-1880, Emory University, Atlanta, 1999, págs. 318-331 y 403-407. 